Www.jmscr.igmpublication.org

Impact Factor (SJIF): 6.379

Index Copernicus Value: 79.54

ISSN (e)-2347-176x ISSN (p) 2455-0450

crossrefDOI: https://dx.doi.org/10.18535/jmscr/v6i10.81

Journal Of Medical Science And Clinical Research

IGM Publication

An Official Publication of IGM Publication

\title{
A retrospective analysis of Peripartum hysterectomy in a tertiary institute, Imphal
}

Authors

\author{
Dr Ratana Usham ${ }^{1}$, Dr Helen Kamei ${ }^{2 *}$, Dr NG Indrakumar Singh ${ }^{3}$ \\ ${ }^{1}$ Assistant Professor, Dept. of Obgyn, JNIMS \\ ${ }^{2}$ Associate Professor, Dept of Obgyn, JNIMS \\ ${ }^{3}$ Professor, Dept of Obgyn, JNIMS \\ *Corresponding Author \\ Dr Helen Kamei \\ Associate Professor, Dept of Obgyn, JNIMS
}

\begin{abstract}
Introduction: Peripartum hysterectomy is performed as a life saving measure for intractable post partum hemorrhage not responding to conservative measures. The incidence of peripartum hysterectomy varies worldwide. In the United States, increase incidence has been noted. In India, various review of peripartum hysterectomy has been reported. The aim of the study is to analyse women undergoing peripartum hysterectomy. It describes the cause and outcome of women undergoing hysterectomy.

Method: A retrospective analysis was carried out for women who underwent peripartum hysterectomy at Jawaharlal Nehru Institute of Medical Sciences from January 2015- September 2018. Data abstraction was done from case files of women who underwent childbirth and obstetric hysterectomy.

Results and Analysis: 20 cases underwent peripartum hysterectomy from January 2015 to September 2018. During this period, a total of 20,327 deliveries were noted. A peripartum hysterectomy rate of $0.1 \%$ was noted. Majority of the women ages ranged between 30-40 years (70\%). Majority of the indications for peripartum hysterectomies were due to placental abnormalities (45\%) and uterine atony (40\%). 2 (10\%) cases of extensive uterine rupture and 1(5\%) case of bleeding diathesis following abruption placenta were noted. Most women had prolonged hospital stay between 7-14days (12 cases). Fever was the most common post operative complication noted. Bladder injury occurred in 3 cases and it was associated with cases that had previous caesarean delivery. Wound sepsis was noted in $40 \%$ (8) cases. Blood transfusion was given in all cases; however 4 cases required massive blood transfusion. Post surgery all patients were observed for 24 hours in Surgical ICU, however, 35\% (7) had prolonged stay in ICU. 10\% (2 cases) maternal mortality was recorded. 3 neonatal mortality and 9 NICU admission was noted.

Conclusion: Good obstetric practice is essential to not only reduce the threshold for caesarean section but subsequently for decreasing the rate of peripartum hysterectomy associated with abnormal placentation consequent to caesarean delivery.

Keywords: Peripartum hysterectomy, uterine atony, abnormal placentation, obstetric hysterectomy, post partum hemorrhage.
\end{abstract}

\section{Introduction:}

Peripartum hysterectomy is a challenging procedure, encountered in emergency situation following childbirth. It is performed following vaginal or caesarean delivery complicated by obstetric haemorrhage, when conservative 
measures have failed. Hence, it is usually an unplanned surgery performed as life saving measures for the mother. Porro first described hysterectomy following caesarean section for post partum haemorrhage.

The incidence of peripartum hysterectomy varies worldwide. In the United States, increase incidence has been noted along with increase of caesarean delivery. In India, various review of peripartum hysterectomy has been reported. The incidence also seems to vary with the mode of delivery with most studies reporting more incidences following caesarean delivery.

The noted risk factors associated with increased risk of peripartum hysterectomy include abnormal placentation, uterine atony, and uterine rupture. Consequent to the emergent situation and surgery, maternal morbidity has been noted in the form of fever, wound infection, DIC, vaginal cuff bleeding, ileus and adnexectomy. Maternal mortality can be avoided with effective and timely intervention of the source of intractable post partum hemorrhage. The aim of the study is to analyse women undergoing peripartum hysterectomy. It describes the cause and outcome of women undergoing hysterectomy.

\section{Method}

A retrospective analysis was carried out for women who underwent peripartum hysterectomy at Jawaharlal Nehru Institute of Medical Sciences from January 2015- September 2018. Data abstraction was done from case files of women who underwent childbirth and obstetric hysterectomy. The case files were obtained from medical record office and each case file was analysed for all patients who underwent peripartum hysterectomy. Demographic details, previous delivery history, indications for peripartum hysterectomy and outcome in terms of Length of hospital stay (LOHS), maternal complications and fetal outcome were recorded. Statistical analysis for categorical variables is expressed as frequency and percentage and mean +/- SD.

\section{Results}

20 cases were recorded, who underwent peripartum hysterectomy from January 2015 to September 2018. During this period, a total of 20,327 deliveries were noted. Of these, vaginal deliveries were $9819(48 \%)$ and caesarean deliveries were 10,508 (51.7\%). Of the 20 cases, 11 cases were preceded by vaginal deliveries and 9 cases were preceded by caesarean deliveries. Hence, a peripartum hysterectomy rate of $0.1 \%$ is noted.

Of the women, who underwent delivery, the age ranged from 20 years to 42 years. Majority of the women ages ranged between $30-40$ years (70\%).

Table 1: Demographic characteristics

\begin{tabular}{|l|c|}
\hline Age(years) & No. of cases \\
\hline $20-30$ & 5 \\
\hline $30-40$ & 14 \\
\hline$>40$ & 1 \\
\hline Parity & 1 \\
\hline P0 & 7 \\
\hline P1 & 8 \\
\hline P2 & 2 \\
\hline P3 & 2 \\
\hline P $\geq 4$ & \\
\hline Booking status & 9 \\
\hline Booked & 11 \\
\hline Unbooked & \\
\hline Previous cesarean delivery & 11 \\
\hline None & 3 \\
\hline One & 6 \\
\hline Two & \\
\hline
\end{tabular}

Majority of the women who underwent peripartum hysterectomy were Para 1 (35\%) and 2(40\%). Of the total number of women who had peripartum hysterectomy, 9 (45\%) women had previous caesarean delivery; 6 had previous two caesarean deliveries and 3 had previous one caesarean delivery. Majority of the total cases were unbooked $11(55 \%)$ compared to 9 cases $(45 \%)$ who were booked.

Table 2: Indications for peripartum hysterectomy

\begin{tabular}{|l|c|}
\hline Indications & No. of cases \\
\hline Placental abnormalities & $9(45 \%)$ \\
\hline Uterine atony & $8(40 \%)$ \\
\hline Uterine rupture & $2(10 \%)$ \\
\hline Bleeding diathesis & $1(5 \%)$ \\
\hline Length of hospital stay(days) & \\
\hline$<7$ & 3 \\
\hline $7-14$ & 12 \\
\hline$>14$ & 5 \\
\hline
\end{tabular}


Majority of the indications for peripartum hysterectomies were due to placental abnormalities (45\%) and uterine atony (40\%). Placental abnormalities include placenta previa and morbidly adherent placenta. In both situations, decision for peripartum hysterectomy was undertaken after conventional measures to control the post partum hemorrhage due to respective situation fails. $2(10 \%)$ cases of extensive uterine rupture and $1(5 \%)$ case of bleeding diathesis following abruption placenta were noted. Both cases of uterine rupture had history of attempted delivery at home.

Post operative complications associated with surgery and the preceding causes were noted. Fever was the most common post operative complication noted. Bladder injury occurred in 3 cases and it was associated with cases that had previous caesarean delivery. Wound sepsis were noted in $40 \%$ (8) cases. Blood transfusion was given in all cases; however 4 cases required massive blood transfusion. Post surgery all patients were observed for 24 hours in Surgical ICU, however, 35\% (7) had prolonged stay in ICU. $10 \%$ (2 cases) maternal mortality was recorded.

Most women had prolonged hospital stay between 7-14days (12 cases). 3 had hospital stay lesser than 7 days duration while 5 cases had over 14 days hospital stay. The length of hospital stay ranged from 5 days to 21 days. A mean of 11.1 days was noted for LOHS.

Three cases of neonatal mortality noted occurred in cases of uterine rupture and abruption. 9 of 17 live new born had NICU admission.

Table 3: Complications associated with peripartum hysterectomy

\begin{tabular}{|l|c|}
\hline Complications & No. of cases \\
\hline Maternal & \\
\hline Bladder injury & 3 \\
\hline Febrile morbidity & 8 \\
\hline Wound sepsis & 7 \\
\hline ICU admission & 2 \\
\hline Mortality & \\
\hline Fetal & 3 \\
\hline Mortality & 9 \\
\hline NICU admission & \\
\hline
\end{tabular}

\section{Discussion}

Peripartum hysterectomy is done as a life saving measure associated with obstetric complications viz. intractable post partum haemorrhage. Various incidences have been noted. Jayaram et al noted 1.7 per 1000 deliveries. ${ }^{1}$ A Tertiary hospital in Nigeria noted a rate of $0.2 \%$; 1 in 439 deliveries $^{2}$. An incidence of 0.41 per 1000 deliveries and 0.77 per 1000 deliveries were noted for united Kingdom and United States respectively ${ }^{3,4}$. In our study, peripartum hysterectomy rate of $0.1 \%$ is noted i.e. 1 case ends in peripartum hysterectomy for every 1,016 deliveries. Majority of the patients fell under the age group 30-40 years (70\%) and Para $1(35 \%) \& 2(40 \%)$. et al in their 14 years evaluation found cases aged 20-40 years with a mean of $30+/-4$ years and majority were multiparas ${ }^{5}$. Aneikan et $\mathrm{al}^{2}$ had similar demography to our study with majority age group belonging to 26-30 years group $(35 \%)$ and low parity para 1 and $2(64 \%)$. Anita et $\mathrm{al}^{6}$ in their study showed majority of parity 3 and 4, unlike Jayaram et al showing low parity as more common.

In our analysis, the difference in booked 9 and unbooked 11 cases was not that much. Aneikan et $\mathrm{al}^{2}$ in their study had $50 \%$ unbooked cases. Jayaram et al $52.63 \%$ booked cases, $45.6 \%$ referred cases and $1.75 \%$ unbooked. This trend seems to reflect that status of booking doesn't seem to define any impact on peripartum hysterectomy. Among the cases in our study, $9(45 \%$ had prior caesarean delivery). This figure seems to reflect a slight difference with Jayaram et al where $52.4 \%$ had previous 1 caesarean section and 7 cases had previous 2 caesarean sections.

On analysing the indications for peripartum hysterectomy in our study, placental abnormalities $(45 \%)$ and uterine atony $(40 \%)$ were common. Though uncommon, coagulopathy (5\%) and extensive uterine rupture (10\%) resulted in peripartum hysterectomy. Jayaram et al had similar common indications atonic post partum hemorrhage (38.5\%) and morbidly adherent placenta $(36.84 \%)$. Allam et $\mathrm{al}^{7}$ concluded abnormal placentation as the main indication for 
peripartum hysterectomy. Aneikan et $\mathrm{al}^{2}$ had extensive uterine rupture $67.8 \%$ as the most common indications followed by uterine atony $17.9 \%$ and abnormal placentation (placenta previa $7.1 \%$ and morbidly adherent placenta $7.1 \%$ ). Lovina S.M. Machado ${ }^{8}$ in her evaluation noted abnormal placentation as the most predominant indication $45-73.3 \%$, followed by uterine atony in $20.6-43 \%$ and uterine rupture in $11.4-45.5 \%$. M Knight evaluation of peripartum hysterectomy indication in the UK noted uterine atony 53\% and morbidly adherent placenta $38 \%$ as leading cause. The recognised factors for peripartum hysterectomy include morbidly adherent and placenta previa, uterine atony. Risk factors for abnormal placentation include prior caesarean deliveries, placenta previa, prior uterine surgery and curettage.

Peripartum hysterectomy is technically challenging procedure and associated with high morbidity. Fever was noted in 11 cases $(61 \%)$. Febrile morbidity $52.63 \%$ was the most common post operative complication seen in Jayaram et al study. Bladder injury noted in our study occurred in 3 cases and are related to morbid adherent placenta and previous caesarean delivery. 2 maternal mortality noted in our study were associated with the underlying emergency obstetric condition rather than the procedure. A 2008 review by $\mathrm{UKOSS}^{9}$ noted maternal mortality of $0.6 \%$. Jayaram review noted a maternal mortality of $12 \%$. The average length of hospital stay in our study was 11.1 days. This figure was comparable to that of Jayaram et al review where a mean 13.72 days of hospital stay was noted.

\section{Conclusion}

Post partum hemorrhage remains the leading cause of maternal mortality and morbidity, despite advances in medical and surgical management for various causes. Increase caesarean rate is also an undeniable fact. Caesarean section has been implicated as one of the risk factors for abnormal placentation. Hence, it is pertinent to realise the consequence of caesarean delivery. Good obstetric practice is essential to not only reduce the threshold for caesarean section but subsequently for decreasing the rate of peripartum hysterectomy associated with abnormal placentation consequent to caesarean delivery. A limitation of our study was that we could not evaluate the role of other factors like previous uterine surgery and curettage.

\section{References}

1. Jayaram $\mathbf{S}$ et al. Int $\mathbf{J}$ Reprod Contracept Obstet Gynecol.2016 Feb;5(2):482-486.

2. Aneikan Monday Abasiattai et al. Pan African Medical Journal. 2013;15:60.

3. Whiteman MK, Kuklina E, Hillis SD, Jamiesson DJ, Meikle SF, Posner SF. Incidence and determinants of peripartum hysterectomy. Obstetrics Gynecology.2006;108(6):1486-92.

4. Knight M. Peripartum hysterectomy in the UK: management and outcomes of the associated hemorrhage. BJOG: An International Journal of Obstetrics and Gynecology.2007;114(11):1380-7.

5. S Tahamina, Mary Daniel, Preetha Gunasegaran. Emergency peripartum hysterectomy: a 14 year experience at tertiary care centre in India J Clin Diagn Res. 2017 Sep;11(9):QC08-11.

6. Kant A, Wadhwani K. Emergency obstetric hysterectomy. Journal of Obstet Gynecol India.2005;55(2):132-4.

7. Allam IS, Gorma IA, Fathi HM, Sukkar GF. Incidence of emergency peripartum hysterectomy in Ain-shams University Maternity Hospital, Egypt:a retrospective study. Arch Gynecol Obstet.2014 Nov;290(5:891-6).

8. Lovina SM Machado. Emergency peripartum hysterectomy: Incidence, Indications, risk factors and outcome. N AM J Med Sci. 2011Aug; 3(8): 358-361.

9. Knight M, Kurinczuk JJ, Spark P, Broklehurst P. Comittee UKOSSS others Cesarean Delivery and peripartum hysterectomy. Obstet Gynecol. 2008;111(1):97-105. 